\title{
AMERICAN CARRION BEETLE RARE AT THE PAS, MANITOBA
}

\author{
WALTER KRIVDA, Box 864, The Pas, Manitoba. R9A 1K8
}

Recently, in sorting and arranging my holdings in burying beetles from Manitoba, some specimens of the carrion beetle were located. Though frequent in the south, this is an undoubted rarity in distribution in these parts.

In some 38 years of collecting insects generally in Manitoba, only five specimens have been taken in The Pas area. These have been associated with gravel beaches and dead fish. Only one specimen was taken and seen each time in the above instances. It ranks as one of our rarest species.

Last summer, for the first time, Necrophila americana was found in numbers at Rocky Lake at Wanless, Manitoba, some 40 miles north of The Pas. These were collected by Michael and Richard LeBlanc of The Pas. Two specimens are in the writer's collection. Here also, the beetles were associated with dead fish or fish offal resulting from the fishermen cleaning their fish. They came in numbers to this food source. They would disappear rapidly into old leaf cover on the shoreline when distured. This may be their natural habitat. This may also explain why they are not more far ranging as are the many other kinds of carrion and burying beetles.

Once the exact habitat is known, some insects prove to be not as rare as previously believed. This can be used as a rule of thumb for a wide range of life forms. The problem is that the precise habitats of many living things are not exactly known.

Ron Hooper found it a surprise to see Necrophila americana taken in The Pas area. There are evidently no Saskatchewan records for this fine beetle. In due course, it will likely be soon discovered in a Saskatchewan location on a gravel beach and associated with dead fish.

Any future mapping of the range of this species by computer should take into consideration its evidently narrowly restricted habitat. Travellers in the north should watch for it. It may range farther north in Canada.

EDITOR'S NOTE - We would appreciate help in locating this species in Saskatchewan. It is $16 \mathrm{~mm}$ long and is brown with a yellow-edged thorax. Report any findings of it (and send specimens) to Ronald. Hooper, Saskatchewan Museum of Natural History, Wascana Park, Regina, Saskatchewan. S4P 3V7

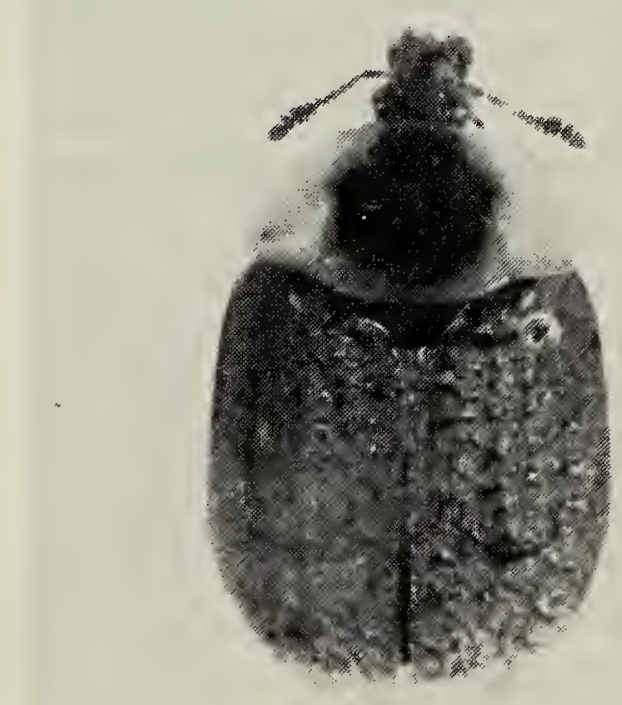

American Carrion Beetle R. Hooper 